\title{
Qualitative exploration of factors influencing the plan selection process by Medicare beneficiaries
}

\author{
Yi Zhao, MPH; Kavon Diggs, PharmD Candidate; Zhen Xing Chen, PharmD Candidate; Natalie Hohmann, PharmD, PhD; \\ Wi-Suk Kwon, PhD; and Salisa C Westrick, PhD
}

\section{What is already known about this subject}

- According to multiple survey and administrative data studies, plan selection decisions by Medicare beneficiaries are not always the most economical, and these decisions might be influenced by costs; coverage of a plan; and beneficiary age, knowledge level, and health status.

- Existing qualitative studies focused on the selection of original Medicare Part D plans, while the selection of Medicare Advantage plans was less studied.

\author{
What this study adds \\ - This study created a step-by-step \\ decision flowchart of Medicare plan \\ selection to illustrate the complexity of \\ making that selection. \\ - The study also created a conceptual \\ model illustrating the Medicare \\ decision-making process and factors \\ that influence the process based on a \\ consumer decision-making model and \\ qualitative study findings.
}

\author{
Author affiliations \\ Yi Zhao, MPH, and Salisa C Westrick, PhD, \\ Department of Health Outcomes Research \\ and Policy, Auburn University Harrison \\ School of Pharmacy, Auburn, AL. Kavon \\ Diggs, PharmD Candidate, and Natalie \\ Hohmann, PharmD, PhD, Department of \\ Pharmacy Practice, Auburn University \\ Harrison School of Pharmacy, Auburn, AL. \\ Zhen Xing Chen, PharmD Candidate, \\ Western New England University College of \\ Pharmacy and Health Sciences, Springfield, \\ MA. Wi-Suk Kwon, PhD, Department of \\ Consumer and Design Sciences, Auburn \\ University College of Human Sciences, \\ Auburn, AL.
}

AUTHOR CORRESPONDENCE:

Salisa C Westrick, 334.844.8314; westrsc@auburn.edu

J Manag Care Spec Pharm 2021;27(3):339-53

Copyright $(2021$, Academy of Managed Care Pharmacy. All rights reserved.

telephone interviews with Alabama residents who have Medicare as the sole insurance provider were conducted between June and August 2019. Participant recruitment continued until reaching the saturation point. Each interview session consisted of structured questions identifying characteristics of participants and open-ended questions used to elicit participant Medicare plan decisionmaking process and factors affecting their decision. Data were analyzed using content analysis with a process of qualitative inductive coding. 
RESULTS: Twenty participants were interviewed. Twenty codes were identified and categorized into 5 themes regarding the factors influencing plan selection decisions by beneficiaries. When making a plan selection, participants were influenced by plan attributes (including cost, coverage, access to doctors, region, quality rating, and transportation); information resources and personal assistance; knowledge about Medicare; status and changes in personal situation; and experience with Medicare. Additionally, we identified 7 codes relating to beneficiary characteristics during decision-making processes, including being proactive, setting priorities, limiting choices, evaluating plans against personal needs, acquiescing to recommendations, sticking to the status quo, and weighing trade-offs. We consulted the CDM and created a conceptual model demonstrating a 5-step Medicare plan selection decision-making process and the factors influencing that process.

CONCLUSIONS: This study created a step-by-step decision flowchart of Medicare plan selection to illustrate the complexity of the plan selection that Medicare beneficiaries must use. We uncovered the plan selection decision-making process among Medicare beneficiaries and factors affecting that process. Drawing from the CDM and the study findings, we developed a conceptual model. Findings will help researchers and community agencies target Medicare beneficiaries with different needs for assistance and design decision-making interventions/tools to help beneficiaries make rational decisions when selecting Medicare plans. These findings suggest that health care professionals should be involved in assistance programs to maximize efficiency of Medicare plan selection and to improve monitoring and consulting mechanisms to ensure the reliability of assistance information and services.

In 2020, Medicare beneficiaries have access to between 24 and 32 stand-alone prescription drug plans (PDPs) and an average of 28 available Medicare Advantage (MA) plans, with 24 of these MA plans including prescription drug coverage (MA-PD). ${ }^{1,2}$ Because plan coverage and costs change from year to year, it is critical for Medicare beneficiaries to review options and make informed decisions every year. ${ }^{3}$

The majority of Medicare beneficiaries (85\%) are adults aged 65 years or older. ${ }^{4}$ Because older adults face multiple health conditions and increasing medical needs, it is important for them to evaluate which plan best meets their multifaceted medical needs every year. ${ }^{5,6}$ However, these evaluations and decisions are complex, as shown in the Medicare decision flowchart (Figure 1). Key influential factors affecting the plan selection process have been reported in published studies using surveys and administrative data. For example, lower costs are associated with higher beneficiary satisfaction with health plans. ${ }^{7,8}$ However, this preference is heterogeneous, as some older adults may prefer plans with higher quality of care over plans with lower cost. ${ }^{9}$ Further, increasing beneficiary age, worse personal health status, and less knowledge about a health plan have been associated with reduced willingness to switch plans. ${ }^{10-13}$

According to decision-making studies, the characteristics of decision makers and the decision task interact to influence the quality of decision making. ${ }^{14}$ As people age, older adults may rely more on rules developed through previous similar experience to make decisions and less on analytic decision making. ${ }^{15,16}$ In addition, complexity and difficulty of a decision-making process rise severely with the increasing number of available choices and smaller differences between options. ${ }^{17,18}$ The possible changes in decision-making strategies and complexity of plan selection may lead to a more difficult decision-making process for some Medicare beneficiaries. . $^{14,19-21}$

Qualitative studies exploring influential factors of the Medicare plan decision-making process have either excluded MA plan beneficiaries from study populations ${ }^{22}$ or explored among a mixed convenience sample who had original Medicare, MA plans, Medicare with private insurance, Medicaid, or Veterans Health Administration benefits. ${ }^{23}$ Because MA plans have gained popularity, ${ }^{24} \mathrm{MA}$ plans provide more options that need to be compared, and beneficiaries can switch between the original Medicare and MA plans, ${ }^{1}$ we did not limit our study scope to Medicare Part D plans but chose to also include MA plan beneficiaries in this study.

This study consulted a 5-step consumer decision-making model (CDM) as guidance to interpret themes emerging from the qualitative data to understand characteristics of the process Medicare beneficiaries employ while making a plan selection decision. The CDM has been commonly used to explain how an individual's rational consumption decision making for a product or service occurs through a sequence of 5 steps: (1) problem/need recognition, (2) information search, (3) alternative evaluation, (4) purchase decision, and (5) postpurchase evaluation. ${ }^{17}$ The model posits that when an individual is aware of the difference between the actual state (e.g., current Medicare plan not covering the desired services) and the desired state (e.g., having a plan that covers the services), a problem/ need arises as the first step of a consumption decision process. This problem/need recognition step then leads to the information search step in which the individual searches for information about available alternatives and important attributes to consider from internal knowledge or external resources or assistance.

In the alternative evaluation step, the individual compares and evaluates the alternatives on key attributes 


\section{FIGURE 1 Medicare Plan Selection Decision-Making Flowchart}

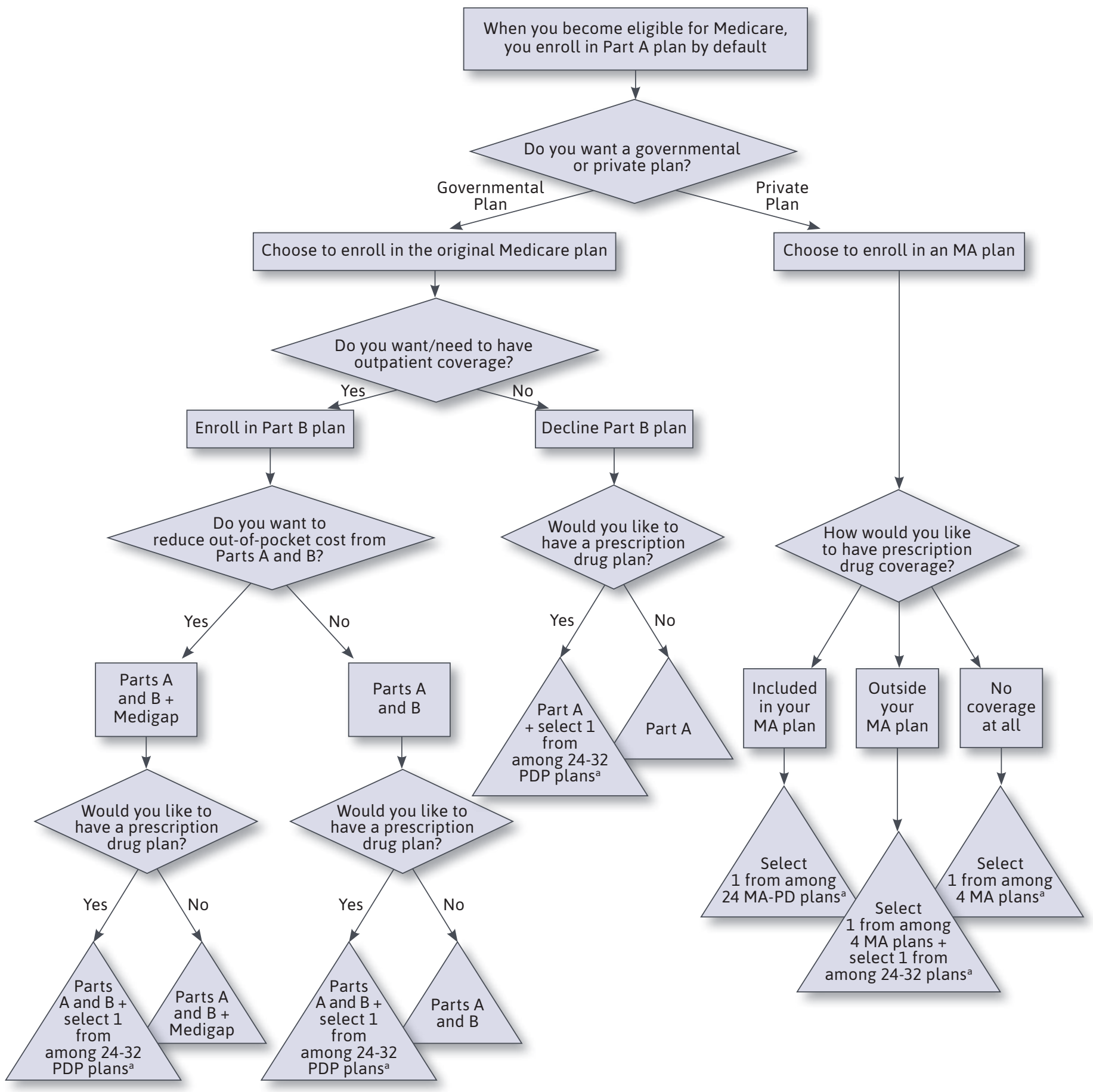

Note: Rectangle/square =chance node, indicates multiple uncertain outcomes; diamond=decision node, indicates a decision to be made; triangle=endpoint node, indicates a final outcome.

aThe number of plans were applied from the numbers of original Medicare and Medicare Advantage plan options in 2020.

$M A=$ Medicare Advantage; $M A-P D=$ Medicare Advantage prescription drug plan; Medigap=Medicare Supplement Insurance plan; $P D P=$ prescription drug $p l a n$. 
considered important according to the searched information (e.g., comparing attributes of more than 20 plans), which may result in a decision to purchase 1 of the alternatives evaluated (e.g., selecting a Medicare plan), which is referred to as the purchase decision step. The individual may continue evaluating the outcome of this decision as he or she uses the purchased product/service, and this postpurchase evaluation step loops the individual back to the first step, problem/need recognition, if dissatisfied.

However, as previously mentioned, not all beneficiary Medicare plan decisions are optimal, which means beneficiaries do not always thoroughly follow the 5-step process postulated by the CDM. ${ }^{25}$ Many individual or environmental factors may interact with the complexity of Medicare options and plans, which can impact beneficiaries' ability or motivation to engage in 1 or more steps of the decisionmaking process, resulting in the decision-making process being less rational.

The purpose of this study was to identify such potential individual, environmental, or plan factors influencing the plan decision-making process by Medicare beneficiaries through a phenomenological investigation. This investigation was guided by 2 research questions: (a) what factors do Medicare beneficiaries consider to have influenced their Medicare plan selection decision and (b) what characteristics do Medicare beneficiaries demonstrate along the decision-making steps outlined in the CDM? ${ }^{25}$

\section{Methods}

\section{STUDY DESIGN AND PARTICIPANTS}

This phenomenological qualitative study was conducted using semistructured telephone or face-to-face interviews. Volunteering participants were eligible if they were Medicare beneficiaries, not covered by Medicaid or current/former employer-sponsored insurance in addition to Medicare, residents of Alabama, and able to read and write in the English language. Participants were recruited in May-July 2019 via a variety of methods, such as flyers, radio announcements, a study website, a press release by the authors' institution, and personal referrals by the Alabama State Health Insurance Assistance Program (SHIP) counselors. Written informed consent was obtained before conducting interviews. To improve recruitment rate and reduce interview "no-shows," a financial incentive in the form of a \$25 electronic gift card was provided to each participant upon interview completion. All procedures were approved as an expedited review by the institutional review board of the authors' institution.

\section{DATA COLLECTION AND MEASURES}

Recruitment continued until reaching the saturation point when no new information was obtained from additional interviews. Each interview session consisted of several structured questions, which addressed participant demographic characteristics, perceived health status, health care utilization and associated costs, preference for vision and dental coverage, and whether they received any help when selecting a health/prescription drug plan, as well as unstructured open-ended questions. The open-ended questions were used to elicit the Medicare plan decisionmaking process employed by participants and factors influencing their plan selection decision. Examples of questions include: "Think back to when you last chose a (Part D plan for Original Medicare patients or Advantage plan for MA patients), how did you choose this plan?" and "Why did you choose to stay with or leave this Medicare plan?"

Quality control procedures were implemented throughout data collection. For example, to gain background knowledge, the 3 interviewers participated in community Medicare plan selection assistance program training sessions. Moreover, the interviewers discussed lessons learned after each interview to ensure adherence to the interview protocol, consistency among interviewers, and that pertinent questions were explored and phrased in manner to best elicit participant responses.

\section{DATA ANALYSIS}

Interviews were digitally audio-recorded, transcribed verbatim, and analyzed in ATLAS.ti version 8.4.2 qualitative data analysis software (ATLAS.ti Scientific Software Development $\mathrm{GmbH}$, Berlin, Germany). For the first research question (i.e., factors influencing beneficiary plan selection decision), the interview transcripts were coded using an inductive process to identify themes using content analysis. ${ }^{26}$ Three rounds of coding were conducted. First, 3 researchers individually used an open coding process to identify patterns within the data of 3 interviews to generate initial codes. Discrepancies in these codes among researchers were resolved via discourse and consensus. In the second round of coding, all transcripts were coded by 2 main coders, after which the researchers reevaluated the codes and identified additional codes. In the last round of coding, researchers consolidated several codes that were similar in nature but had low frequency $(f)$. Finalized codes were agreed upon by all researchers for a total of 20 codes, which were clustered into 5 broad themes.

For the second research question (i.e., beneficiary decision-making process characteristics according to the $\mathrm{CDM}$ ), a mixed inductive and deductive approach was used. First, the same inductive content analysis procedure 
involving 3 coding rounds was employed to identify and finalize the codes for participant decision-making characteristics that emerged from the data. This procedure resulted in 7 final codes under the single theme of decisionmaking process. Next, the 7 decision-making process codes were deductively reviewed against the 5 decision-making steps postulated by the CDM. Through discussion and negotiation, the researchers reached agreement on the primary CDM step that each decision-making characteristic code best represented, along with other CDM steps that were of secondary relevance to the code. In making the determination of secondary CDM steps for each code, the researchers considered which other CDM steps besides the primary step would either influence or be influenced by the characteristic addressed by the code.

For the 27 codes, Krippendorff's coefficient of 0.76 was obtained to establish the interrater reliability between the 2 main coders. ${ }^{27}$ In addition, a final quality control review was completed by the third coder by reviewing randomly selected quotes to ensure that each quote was in congruence with the definition of the respective code.

\section{Results}

A total of 20 Medicare beneficiaries were interviewed, 19 via telephone and 1 in person during June-August 2019 (Table 1). The average age of participants was 69.2 years $(\mathrm{SD}=7.12)$. The majority of participants were White $(80 \%)$, lived in urban areas (65\%), and had monthly household income of $\$ 2,500$ or less $(55 \%)$. In terms of health care needs, most had good self-evaluated health status (75\%), used 5 or fewer prescription medications (60\%), and rated monthly medical expenses as a minor financial burden (80\%).

We identified 20 codes, which we categorized into 5 themes addressing the first research question (i.e., factors influencing beneficiary plan selection decisions)-plan attributes, information sources, knowledge, personal situation, and experience (Table 2). We also used CDM as the guideline to interpret 7 codes related to the decision-making process theme, which answered the second research question (i.e., beneficiary characteristics during decision-making processes; Table 3). Using the findings obtained from the analyses, we also proposed a conceptual model displaying the Medicare decision-making process and influential factors affecting plan decisions. The themes and conceptual model are further discussed in the remaining sections.

\section{INFLUENTIAL FACTORS IN MEDICARE DECISION MAKING}

Plan Attributes. Plan attributes refer to characteristics of Medicare plans that influenced participant selection of their

\section{TABLE 1 Participant Characteristics}

\section{Participant Characteristics $(\mathbf{N}=\mathbf{2 0})$}

\begin{tabular}{|c|c|c|}
\hline Age, years, mean (SD) & 69.20 & $(7.12)$ \\
\hline \multicolumn{3}{|l|}{ Sex, n (\%) } \\
\hline Male & 11 & (55) \\
\hline Female & 9 & $(45)$ \\
\hline \multicolumn{3}{|l|}{ Race, n (\%) } \\
\hline White & 16 & $(80)$ \\
\hline African American & 4 & $(20)$ \\
\hline \multicolumn{3}{|l|}{ Educational level, n (\%) } \\
\hline High school graduate & 4 & (20) \\
\hline 2-year college degree & 9 & $(45)$ \\
\hline 4-year college degree & 6 & (30) \\
\hline Master degree & 1 & (5) \\
\hline \multicolumn{3}{|l|}{ Locationa, n (\%) } \\
\hline Urban & 13 & $(65)$ \\
\hline Rural & 7 & (35) \\
\hline \multicolumn{3}{|c|}{ Persons living in household, $\mathrm{n}(\%)$} \\
\hline 1 & 9 & $(45)$ \\
\hline 2 & 10 & (50) \\
\hline 3 or more & 1 & (5) \\
\hline
\end{tabular}

Monthly household income, $\mathrm{n}(\%)$

\begin{tabular}{l|rr}
\hline Less than $\$ 1,000$ & 1 & $(5.56)$ \\
\hline$\$ 1,001-1,500$ & 2 & $(11.11)$ \\
\hline$\$ 1,501-2,000$ & 5 & $(27.78)$ \\
\hline$\$ 2,001-2,500$ & 2 & $(11.11)$ \\
\hline More than $\$ 2,500$ & 8 & $(44.44)$ \\
\hline
\end{tabular}

Been hospitalized within the year, $\mathrm{n}(\%)$

\begin{tabular}{l|rr}
\hline Yes & 3 & $(15)$ \\
\hline No & 17 & $(85)$ \\
\hline Doctor visits within the year, $\mathbf{n}(\%)$ &
\end{tabular}

Doctor visits within the year, $\mathrm{n}(\%)$

\begin{tabular}{l|rc}
\hline 2 or fewer & 2 & $(10)$ \\
\hline 3 & 6 & $(30)$ \\
\hline 4 & 2 & $(10)$ \\
\hline 5 or more & 10 & $(50)$ \\
\hline Current prescriptions, $\mathbf{n}(\%)$ & 4 & $(20)$ \\
\hline 0 & 4 & $(20)$ \\
\hline 1 to 3 & 4 & $(20)$ \\
\hline 4 to 5 & 8 & $(40)$ \\
\hline 6 or more & & \\
\hline
\end{tabular}

continued on next page 


\section{TABLE 1 Participant Characteristics (continued)}

Participant Characteristics $(\mathrm{N}=20)$

\begin{tabular}{|c|c|c|}
\hline \multicolumn{3}{|c|}{ Total monthly out-of-pocket medication cost, n (\%) } \\
\hline Less than $\$ 50$ & 14 & $(70)$ \\
\hline$\$ 51-100$ & 3 & $(15)$ \\
\hline More than $\$ 100$ & 3 & (15) \\
\hline \multicolumn{3}{|c|}{ Burden of monthly medical expenses on budget, $n(\%)$} \\
\hline None & 4 & $(20)$ \\
\hline A little & 10 & $(5)$ \\
\hline A moderate amount & 2 & $(10)$ \\
\hline A lot & 4 & $(20)$ \\
\hline \multicolumn{3}{|c|}{ Receive financial assistance for health insurance, $n(\%)$} \\
\hline Yes & 4 & $(20)$ \\
\hline No & 16 & $(80)$ \\
\hline \multicolumn{3}{|c|}{ Preference for vision and dental, n (\%) } \\
\hline Prefer to have included & 15 & $(83.33)$ \\
\hline Prefer to purchase separately & 3 & $(16.67)$ \\
\hline \multicolumn{3}{|c|}{ Received help when selecting a Medicare plan, n (\%) } \\
\hline Yes & 9 & $(45)$ \\
\hline No & 11 & $(55)$ \\
\hline \multicolumn{3}{|c|}{ Consider receiving help in selecting plan in future, $n(\%)$} \\
\hline Yes & 17 & $(85)$ \\
\hline No & 3 & $(15)$ \\
\hline \multicolumn{3}{|c|}{ Willing to switch if a more suitable plan is available, $n(\%)$} \\
\hline Definitely yes & 7 & $(35)$ \\
\hline Probably yes & 6 & $(30)$ \\
\hline Might or might not & 2 & (10) \\
\hline Probably not & 4 & $(20)$ \\
\hline Definitely not & 1 & (5) \\
\hline \multicolumn{3}{|c|}{ Rating of current health status, $n$ (\%) } \\
\hline Poor & 3 & $(15)$ \\
\hline About average & 3 & (15) \\
\hline Good & 13 & (65) \\
\hline Excellent & 1 & (5) \\
\hline
\end{tabular}

${ }^{a}$ Degree of rurality was classified based on 2013 Rural-Urban Continuum codes. Codes 1-4 were defined as urban areas, 5 and above as rural areas.

Medicare plan. This theme appeared the most frequently across and within all transcripts $(f=379)$. Six codes fall into this theme, including cost, coverage, access to doctors, region, quality rating, and transportation. As expected, cost and coverage were the most identified codes in the interviews. For example, 1 beneficiary explained that switching from a plan that cost $\$ 800$ per month to a different plan that cost $\$ 135$ per month was really satisfying.

Information Sources. Information sources describe the resources or people that participants indicated influenced their Medicare plan selection decision $(f=168)$. Three codes belonged to this theme-resources and assistance, friends and family, and spouse. All 20 participants mentioned that their decisions were influenced by information obtained through resources (e.g., Medicare.gov website) or personal assistance (e.g., SHIP counselors, insurance agents). For example, 1 participant went through Medicare.gov every year and input all his medications to find a plan that had the best price for him. Moreover, $70 \%$ and $40 \%$ of participants said that their friends/family and spouse, respectively, impacted their decisions.

Knowledge. The data revealed that knowledge was the most frequently mentioned individual factor theme $(f=270)$ that influenced the Medicare decision-making process. This theme encompassed 4 codes-knowledge on existing plan, limited knowledge, resource confusion, and plan coverage confusion. Although all 20 participants had some knowledge of their existing plan, all of them also admitted that their knowledge about Medicare was limited in some respects. Particularly, $70 \%$ of interviewees expressed confusion experienced while trying to comprehend Medicare-related resources (e.g., Medicare.gov), whereas $30 \%$ of participants pointed out their confusion about the coverage of the plan they chose.

Personal Situation. The second individual factor theme, personal situation, refers to the status and changes in beneficiaries' medical or other conditions that affect their Medicare decision making. This theme included 4 codes: health care utilization, length of enrollment, switch from previous plan, and change in eligibility from non-Medicare plans. Among the 4 codes, health care utilization was the most frequent code $(f=71)$, as most participants $(85 \%)$ took this into consideration when they made a plan selection decision. For example, an interviewee mentioned that he was willing to pay a little more each month, but because he was in good health, he was not worried about having to pay a little bit of extra money for peace of mind. The other 3 codes were also mentioned by $70 \%-90 \%$ of the interviewees but with less frequency $(30<f<34)$.

Experience. The experience theme included 2 codespositive plan experiences and negative plan experiences. Almost all participants (90\%) had positive plan experience and thought that their needs were generally met, whereas $40 \%$ of the participants expressed some aspects of their plan that were not satisfactory. 


\section{TABLE 2 Themes and Codes for Factors Influencing Medicare Plan Selection Decision}

\begin{tabular}{|c|c|c|c|c|}
\hline Topic & Code & $f^{a}$ & $\begin{array}{l}\text { Interviewees, } \\
\mathrm{n}(\%)^{\mathrm{b}}\end{array}$ & Representative Quotes ${ }^{\mathrm{C}}$ \\
\hline \multirow[t]{11}{*}{$\begin{array}{l}\text { Plan attributes } \\
(\mathrm{n}=379)\end{array}$} & \multirow[t]{3}{*}{ Cost } & \multirow[t]{3}{*}{190} & \multirow[t]{3}{*}{$20(100)$} & $\begin{array}{l}\text { "I honestly don't remember which one was the more expensive, but it seems } \\
\text { like there wasn't very much..." (M1, 77, W) }\end{array}$ \\
\hline & & & & $\begin{array}{l}\text { "Well, after coming from } 800 \text { dollars to } 135 \text { dollars, I was really pleased, very } \\
\text { pleased." (M3, 67, W) }\end{array}$ \\
\hline & & & & $\begin{array}{l}\text { "Cost and benefits, I guess is the best thing. I didn't choose <name of the } \\
\text { plan }>\text {. If you all want to know the truth, my insurance was cheaper before } \\
\text { going on Medicaid." (M7, 87, W) }\end{array}$ \\
\hline & \multirow[t]{2}{*}{ Coverage } & \multirow[t]{2}{*}{90} & \multirow[t]{2}{*}{19 (95) } & $\begin{array}{l}\text { "And I haven't seen anything come in the mail to tell him that, hey you can get } \\
\text { you some dentures or we would give you so much on your glasses if you wore } \\
\text { glasses. But, that kind of stood out to me about the glasses and the dentures } \\
\text { because that is primarily what I need right now." (F15, 67, A) }\end{array}$ \\
\hline & & & & $\begin{array}{l}\text { "Yeah, I think it is because I don't think that this drug is covered under most } \\
\text { plans. It's naltrexone and it's relatively new. It was like a last-ditch effort to } \\
\text { help me with my chronic pain and so I think it would cost } \$ 40 \text { under any plan. } \\
\text { That's just my opinion." (F19,67, W) }\end{array}$ \\
\hline & \multirow[t]{2}{*}{ Access to doctors } & \multirow[t]{2}{*}{57} & \multirow[t]{2}{*}{$17 \quad(85)$} & $\begin{array}{l}\text { "I would consider another plan if I could keep my doctors. That's my number } \\
\text { one, you know, big thing." (F19, 67, W) }\end{array}$ \\
\hline & & & & $\begin{array}{l}\text { "Well, I was looking at one of them, and then I got a deluge of them. Everybody } \\
\text { was trying to call me. And, basically, there were two or three that I did end up } \\
\text { talking to, all told me that I had to switch doctors or I, "Wasn't going to be get- } \\
\text { ting this, I couldn't do this. It's not benefiting me to switch." (M5, 68, W) }\end{array}$ \\
\hline & Region & 31 & $12(60)$ & $\begin{array}{l}\text { "Yeah, sometimes we have to go there < outside the area > for surgery. Because } \\
\text { they don't have all the specialist and surgeries in our area?" (F11, 83, W) }\end{array}$ \\
\hline & \multirow{2}{*}{$\begin{array}{l}\text { Quality rating } \\
\text { (star rating) }\end{array}$} & \multirow[t]{2}{*}{10} & \multirow[t]{2}{*}{$8(40)$} & "I would look at the four- and five-star ratings." (F18, 62, W) \\
\hline & & & & $\begin{array}{l}\text { "Right. I would be interested in why one had a higher star rating. It would take } \\
\text { quite a bit I think for me to change because my experience has been good." } \\
\text { (M1, } 77, \mathrm{~W})\end{array}$ \\
\hline & Transportation & 1 & $(5)$ & $\begin{array}{l}\text { "And anything like I don't drive. It'll be nice where I can get transportation." } \\
(\mathrm{M} 5,68, \mathrm{~W})\end{array}$ \\
\hline \multirow[t]{7}{*}{$\begin{array}{l}\text { Information } \\
\text { sources } \\
(n=168)\end{array}$} & \multirow[t]{3}{*}{$\begin{array}{l}\text { Resources and } \\
\text { assistance }\end{array}$} & \multirow[t]{3}{*}{124} & \multirow[t]{3}{*}{$20(100)$} & $\begin{array}{l}\text { "I try to make anything as simple as I can. What I looked at like on Medicare. } \\
\text { gov, I think it is as far as cost and coverage and all. I just never did think it was } \\
\text { a big maze to work through because I knew what I wanted to be covered and } \\
\text { it was pretty much laid out. Yes, we will or no, we won't. I just selected a plan." } \\
\text { (M1, } 77, \text { W) }\end{array}$ \\
\hline & & & & $\begin{array}{l}\text { "I've talked to some of them < Insurance agents > and they have different insur- } \\
\text { ance companies so it's just... I've never really had to use it that much. Just a } \\
\text { little bit. And they've been pretty good on everything." (F2, 72, W) }\end{array}$ \\
\hline & & & & $\begin{array}{l}\text { "Well, I'd say SHIP because that's their profession. She goes to other counties } \\
\text { and works with older people. You know more about SHIP, I guess, than I do." } \\
(\mathrm{M7}, 83, \mathrm{~W})\end{array}$ \\
\hline & \multirow[t]{2}{*}{ Friends and family } & \multirow[t]{2}{*}{31} & \multirow[t]{2}{*}{$14 \quad(70)$} & $\begin{array}{l}\text { "Well, yeah. I would certainly lean on people I trust that were close to me. We } \\
\text { have several close friends. I would listen to them. I would take some advice } \\
\text { from them. And my two sons, the pharmacy is totally... I've turned it over to } \\
\text { them. They totally own the pharmacy now. They're a lot smarter than I am. At } \\
\text { least they think they are. No, I'm just kidding. They are, I would listen to their } \\
\text { advice for sure, yes." (M6, } 69, \mathrm{~W})\end{array}$ \\
\hline & & & & $\begin{array}{l}\text { "Well, I'd talked to some family members and some friends. The pharmacy had } \\
\text { an insurance specialist agent, and he sort of worked with me and we went over } \\
\text { several of the plans." (F18, 62, W) }\end{array}$ \\
\hline & \multirow[t]{2}{*}{ Spouse } & \multirow[t]{2}{*}{13} & \multirow[t]{2}{*}{$8 \quad(40)$} & $\begin{array}{l}\text { "I think they administer it for Medicaid, Medicare, don't they? Medicaid, what- } \\
\text { ever. I don't understand all this now, please don't take me seriously. My wife } \\
\text { understands this a lot more so than I do." (M14, 71, W) }\end{array}$ \\
\hline & & & & $\begin{array}{l}\text { "She }<\text { wife }>\text { played a great part in it, and last year they dropped my UAB doc- } \\
\text { tors and that's where I go to the cardiologist. So, we took this new plan this } \\
\text { year to cover to make sure that we could go to the University." (M14, 71, W) }\end{array}$ \\
\hline
\end{tabular}




\begin{tabular}{|c|c|c|c|c|}
\hline Topic & Code & $f^{a}$ & $\begin{array}{c}\text { Interviewees, } \\
\text { n (\%) }\end{array}$ & Representative Quotes $^{\mathrm{C}}$ \\
\hline \multirow[t]{9}{*}{$\begin{array}{l}\text { Knowledge } \\
(\mathrm{n}=270)\end{array}$} & \multirow[t]{3}{*}{$\begin{array}{l}\text { Knowledge of } \\
\text { existing plan }\end{array}$} & \multirow[t]{3}{*}{153} & \multirow[t]{3}{*}{$20(100)$} & $\begin{array}{l}\text { "I went with the }<\text { Medigap > plan } F \text {, which is a more expensive monthly plan, } \\
\text { but it pays. It probably balances out over the year, but once I pay my insurance, } \\
\text { I don't have to worry about copays and that type of thing." (MI, 77, W) }\end{array}$ \\
\hline & & & & $\begin{array}{l}\text { "It has. I think when I started, it started at } 134 \text { dollars, I believe. And now I } \\
\text { think it's had two changes since I've had it. I've had it a little over a year, I'm } \\
\text { getting into my second year, and I think it's like, } 151 \text { now, so yeah, there's been } \\
\text { some increase." (M3, 67, W) }\end{array}$ \\
\hline & & & & $\begin{array}{l}\text { "So right now, I've got some back problems, so I'm doing physical therapy. } \\
\text { Medicare covers physical therapy better than < name of previous plan > did. So, } \\
\text { a little bit of that extent." }(\mathrm{M} 6,69, \mathrm{~W})\end{array}$ \\
\hline & \multirow[t]{2}{*}{$\begin{array}{l}\text { Limited } \\
\text { knowledge }\end{array}$} & \multirow[t]{2}{*}{72} & \multirow[t]{2}{*}{$20(100)$} & $\begin{array}{l}\text { "And I can't remember now exactly what the benefits were, exactly. I know that } \\
\text { it ... I think it may be less deductibles. And I think that might have been the big- } \\
\text { gest thing, it had maybe a zero deductible." (M3,67, W) }\end{array}$ \\
\hline & & & & $\begin{array}{l}\text { "Well, I really don't have a hard time by going on the website, but when I get on } \\
\text { the website, it might be some things that on there that I might not understand. } \\
\text { I would have to have somebody to explain it to me." (F8,66, A) }\end{array}$ \\
\hline & \multirow[t]{2}{*}{$\begin{array}{l}\text { Resource } \\
\text { confusion }\end{array}$} & \multirow[t]{2}{*}{35} & \multirow[t]{2}{*}{$14 \quad(70)$} & $\begin{array}{l}\text { "Well, it's what's covered, what's not covered. I mean, they }<\text { Medicare }>\text { sent } \\
\text { me a book that's a couple of hundred and some pages." }(M 5,68, W)\end{array}$ \\
\hline & & & & $\begin{array}{l}\text { "Oh yes, it's very confusing in the Fall when they come out with all these differ- } \\
\text { ent plans." (F11, } 83, \mathrm{~W})\end{array}$ \\
\hline & \multirow[t]{2}{*}{$\begin{array}{l}\text { Plan coverage } \\
\text { confusion }\end{array}$} & \multirow[t]{2}{*}{10} & \multirow[t]{2}{*}{$8 \quad(40)$} & $\begin{array}{l}\text { "Well, I didn't know really until I got my new policy for the new year and I was } \\
\text { reading it and then I discovered that there had been an increase. These have } \\
\text { evolved over years, they get bigger." (F13, } 71, \mathrm{~W})\end{array}$ \\
\hline & & & & $\begin{array}{l}\text { "No, they have not. A lot of times they'll ask people to change a whole bunch } \\
\text { of their medications. I ran across one or two since then that they wouldn't do } \\
\text { them, but it was not a problem, it's the same therapeutic category, and I didn't } \\
\text { mind at all. But it has not been a problem. They have not asked me to change } \\
\text { much of anything." }(\mathrm{M} 6,69, \mathrm{~W})\end{array}$ \\
\hline \multirow[t]{10}{*}{$\begin{array}{l}\text { Personal situation } \\
(\mathrm{n}=181)\end{array}$} & \multirow[t]{3}{*}{$\begin{array}{l}\text { Anticipated health } \\
\text { care utilization }\end{array}$} & \multirow[t]{3}{*}{71} & \multirow[t]{3}{*}{$17 \quad(85)$} & $\begin{array}{l}\text { "Yes. I'm very ... Like I say, it costs a little bit more per month, but then I think } \\
\text { the fact that I am in good health, that it's a better plan for me." (M1, 77, W) }\end{array}$ \\
\hline & & & & $\begin{array}{l}\text { "So anyway, I've changed it, but if I thought I was going to have health prob- } \\
\text { lems, or my health was bad, I wouldn't keep it." (M3,67, W) }\end{array}$ \\
\hline & & & & $\begin{array}{l}\text { "Well, no. I mean, basically, I really have no idea or know anything about } \\
\text { Medicare. All I know is that I needed a plan to be covered because I was sick, } \\
\text { and I knew I was going to have medical expenses so I took what I could see. } \\
\text { When I talked to somebody ... I called." (M5, } 68, \mathrm{~W})\end{array}$ \\
\hline & $\begin{array}{l}\text { Length of } \\
\text { enrollment }\end{array}$ & 34 & $18 \quad(90)$ & $\begin{array}{l}\text { "Well, } 65 \text { to } 83 \text {. That's 20. That's, yeah. That's } 18 \text { years. Yeah." (M7, 83, W) } \\
\text { "On < name of plan>? I've been on it about four years." (F13, 71, W) }\end{array}$ \\
\hline & \multirow[t]{2}{*}{$\begin{array}{l}\text { Switch from } \\
\text { previous plan }\end{array}$} & \multirow[t]{2}{*}{31} & \multirow[t]{2}{*}{$16 \quad(80)$} & $\begin{array}{l}\text { "<Plan name }>\text {, I had that before. I moved real estate from Phenix City to Lee } \\
\text { County. Anyway, I went to a couple of doctors up here and they didn't take } \\
<\text { name of plan }>\text {, so I had to switch over." (F8,66, A) }\end{array}$ \\
\hline & & & & $\begin{array}{l}\text { "Well, yes it did < switch the plan }>\text { and the reason it did because otherwise } \\
\text { in the package that I got from the state of North Carolina when I moved back } \\
\text { here, that's why I went with < plan name >." (M10, 71, W) }\end{array}$ \\
\hline & \multirow{2}{*}{$\begin{array}{l}\text { Change in } \\
\text { eligibility from } \\
\text { non-Medicare } \\
\text { plans }\end{array}$} & \multirow[t]{2}{*}{30} & \multirow[t]{2}{*}{$14 \quad(70)$} & $\begin{array}{l}\text { "But I was working, then I would lose my health insurance and all of that. I lose } \\
\text { everything. So, I had to apply for Medicare." }(M 20,63, A)\end{array}$ \\
\hline & & & & $\begin{array}{l}\text { "Since I was, what is it, } 65 \text { ? That you start on Medicare? Or 62? I started getting } \\
\text { Social Security at 62." (F2, 72, W) }\end{array}$ \\
\hline & \multirow[t]{2}{*}{ Income } & \multirow[t]{2}{*}{15} & \multirow[t]{2}{*}{$6 \quad(30)$} & $\begin{array}{l}\text { "But at the moment I have Medicare and I don't qualify for Medicaid because } \\
\text { they say I have too much money." (M10, } 71, \text { W) }\end{array}$ \\
\hline & & & & “Right, so I couldn't afford a plan." (F15, 67, A) \\
\hline
\end{tabular}




\section{TABLE 2 Themes and Codes for Factors Influencing Medicare Plan Selection Decision (continued)}

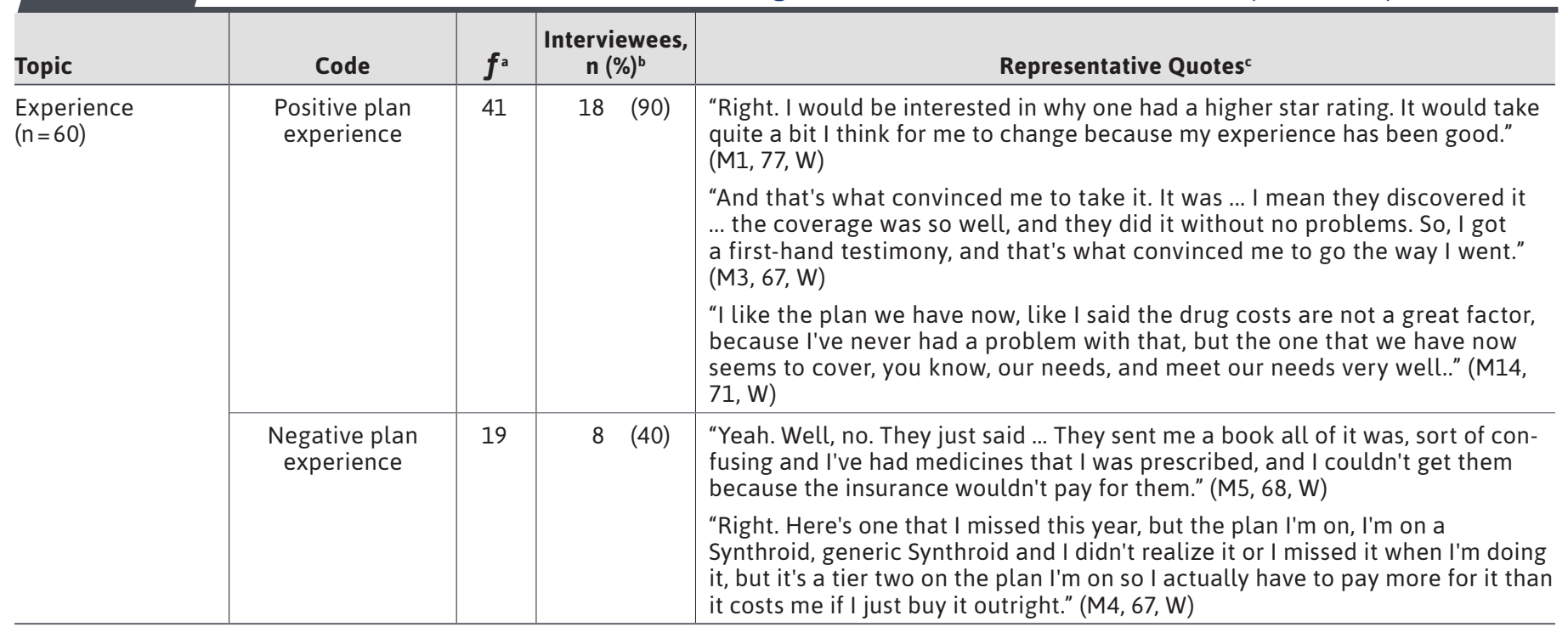

${ }^{a}$ Frequency of codes mentioned.

${ }^{b}$ Number of participants who mentioned the code at least once.

'Respondent characteristics are indicated in parentheses (sex and participant number, age, race).

$A=$ African American; $F=$ female; $M=$ male; $W=$ White.

\section{DECISION-MAKING PROCESS}

Seven associated codes constituted the decisionmaking process theme. These codes illustrate interviewees' self-reported cognitive or behavioral characteristics during their Medicare plan decision-making process. Table 3 presents the codes and how the CDM-based decisionmaking steps directly or indirectly related to each of the codes. One code (being proactive) was identified as primarily related to the information search (IS) step of the decision-making process. About half $(55 \%)$ of the interviewees expressed some proactive actions they took in seeking information to help their decision making, which is a sign of a rational decision maker.

In addition, 3 codes (setting priorities, limiting choices, and evaluating plans against personal needs) emerged as primarily related to the alternative plan evaluation (APE) step of the decision-making process. The evaluation of a plan against personal needs was a key factor in terms of the code frequency $(f=215)$, with all interviewees mentioning at least 1 quote that met this code definition. Plan evaluation happened when participants considered the fit between their health care needs and the plan characteristics. For example, 1 participant explained that he chose a plan that had a deductible because he was in good health. Next, the second most frequent code related to the APE step was setting priorities for what was important to participants. Most participants (85\%) explained various characteristics of the plan and identified factors that were important. For example, 1 interviewee's priority was the ability to choose her own doctor, whereas another interviewee prioritized plans that covered her pricey medications. Finally, some interviewees (40\%) expressed how they eliminated some Medicare program choices or plan options to narrow down their consideration set based on their priorities. For example, 1 interviewee said, "I usually try to look at what I think would pertain to me and go with that." Setting priorities, limiting choices based on the priorities, and evaluating alternatives against these personal priorities are characteristics of a rational decision maker in efforts to streamline the alternative evaluation step in a complex decision environment as in Medicare plan decisions.

Finally, primarily related to the plan selection decision (PSD) step of the Medicare decision-making process, 3 (weighing trade-offs, sticking to the status quo, and acquiescence to recommendations) emerged. Despite many interviewees' showing potential rational decisionmaking characteristics relevant to the IS and APE steps as described above, only $20 \%$ indicated that their final PSD step involved weighing trade-offs among 2 or more key plan attributes to choose a plan among multiple options. The 


\begin{tabular}{|c|c|c|c|c|}
\hline Code & $\begin{array}{l}\text { CDM Steps: } \\
\text { Primary } \\
\text { (Secondary) }^{\text {(Secor }}\end{array}$ & $f^{\mathrm{b}}$ & $\begin{array}{c}\text { Interviewees, } \\
\mathbf{n}(\%)^{\mathbf{c}}\end{array}$ & Representative Quotes ${ }^{d}$ \\
\hline Being proactive & $\begin{array}{c}\text { IS } \\
(\mathrm{PNR}, \mathrm{APE})\end{array}$ & 32 & $11 \quad(55)$ & $\begin{array}{l}\text { "Yeah, I do. Each year I look at ... On Medicare.gov it shows supposedly what } \\
\text { their annual expense is. That's including the donut hole, so I usually look at } \\
\text { that to determine what my total annual expense is going to be, try to pick the } \\
\text { least amount." (M4, } 67, \mathrm{~W}) \\
\text { "But anyway, the only thing that's going up is, like I said, is the Part B of } \\
\text { Medicare. So, until < name of plan > gives me a reason, and if they jump up, } \\
\text { then I'll look at it at the end of the year." (M6, } 69, \mathrm{~W})\end{array}$ \\
\hline Setting priorities & $\begin{array}{c}\text { APE } \\
\text { (IS, PSD) }\end{array}$ & 49 & $17 \quad(85)$ & $\begin{array}{l}\text { "Yeah, I prefer to choose my own doctor." }(\mathrm{F} 8,66, \mathrm{~A}) \\
\text { "Oh, it's everything really. It < medication coverage }>\text { would rank higher than } \\
\text { the doctor copays, because of ... there's two of my medications that are really } \\
\text { expensive, and then the arthritis shot that I'll take is just outrageous. So, it's } \\
\text { probably the first thing I would make sure that my medications would be cov- } \\
\text { ered." (F18, 62, W) }\end{array}$ \\
\hline Limiting choices & $\begin{array}{c}\text { APE } \\
\text { (IS, PSD) }\end{array}$ & 13 & $8 \quad(40)$ & $\begin{array}{l}\text { "The hospital plans, unless you're going to go with an Advantage plan, with the } \\
\text { regular Medicare, that's pretty well set. Without looking at Advantage, there's } \\
\text { not a whole lot other than the supplement that you can look at with regular } \\
\text { Medicare..." (M4, } 67, \mathrm{~W}) \\
\text { "In Alabama, really if you want to have good choice of where to go, <name of } \\
\text { insurance company } 1>\text { about got the market setup. You don't really have a lot } \\
\text { of choice with the C+. There was C+ in < name of insurance company } 2>\text {. I guess } \\
\text { <name of insurance company } 2>\text { is still doing it. I just like C+." (F15, } 67, \mathrm{~A})\end{array}$ \\
\hline $\begin{array}{l}\text { Evaluating plans } \\
\text { against personal } \\
\text { needs }\end{array}$ & $\begin{array}{c}\text { APE } \\
\text { (PNR, IS) }\end{array}$ & 215 & $20(100)$ & $\begin{array}{l}\text { "What I look at their yearly, does this plan still cover what medications I am } \\
\text { taking? Does it cover what I might I would anticipate having to take? As long as } \\
\text { it does that, I have no reason to change." (MI, } 77, \mathrm{~W}) \\
\text { "Well, on this plan I got now, the biggest reason that I went to a plan that had a } \\
\text { deductible was because I am in good health." }(\mathrm{M} 3,67, \mathrm{~W})\end{array}$ \\
\hline $\begin{array}{l}\text { Acquiescence to } \\
\text { recommendations }\end{array}$ & $\begin{array}{c}\text { PSD } \\
\text { (PNR, IS, APE) }\end{array}$ & 7 & $5 \quad(25)$ & $\begin{array}{l}\text { "Well, you know, last year I become eligible for Medicare, so that's when I } \\
\text { dropped < plan name }>\text { and went with < plan name }>\text {. And my mother, she has } \\
\text { the same insurance. A friend of mine has got it, and they've both used it pretty } \\
\text { extensively and they were well satisfied with it." (M3, 67, W) } \\
\text { "... and then when it was said to me in the letter, they didn't give me much of a } \\
\text { choice. They said, "This is the plan that we have. That we can put you on." } \\
(\mathrm{M} 5,68, \mathrm{~W})\end{array}$ \\
\hline $\begin{array}{l}\text { Sticking to the } \\
\text { status quo }\end{array}$ & $\begin{array}{c}\text { PSD } \\
\text { (PNR, IS, APE, PDE) }\end{array}$ & 28 & $13(65)$ & $\begin{array}{l}\text { "I wouldn't change or decreasing the benefits, because right now, they all work } \\
\text { fairly well. (F18, 62, W) } \\
\text { "It's just been real good plan; I haven't had any problem with it." (F17, 72, W) }\end{array}$ \\
\hline $\begin{array}{l}\text { Weighing } \\
\text { trade-offs }\end{array}$ & $\begin{array}{c}\text { PSD } \\
\text { (PNR, IS, APE) }\end{array}$ & 13 & $4 \quad(20)$ & $\begin{array}{l}\text { "I want to be able to use my doctors if I have to pay maybe even twice as much, } \\
\text { that's worth it to me, to be able to use the doctors I want." (M3, } 67, \text { W) } \\
\text { "I've got some cardiac problems, if something happened where I needed a lot } \\
\text { more hospitalization, then, yeah, that would play a factor in it. I would have } \\
\text { to look at deductibles and what's going to come out best coverage in that } \\
\text { scenario. But I'd have to look at overall cost. The deductible, I wouldn't go with } \\
\text { say a } \$ 25,000 \text { deductible for just catastrophic coverage. I want to be covered } \\
\text { for almost everything. I would probably go with a premium that gives me the } \\
\text { best overall coverage. Of course with Medicare, the part B specify what's cov- } \\
\text { ered and what's not and what your deductibles are." (M5, } 67, \mathrm{~W})\end{array}$ \\
\hline
\end{tabular}

aSteps of Medicare decision-making process primarily (secondarily) related to the code (see Figure 2).

${ }^{b}$ Frequency of codes mentioned.

'Number of participants who mentioned the code at least once.

${ }^{d}$ Respondent characteristics are indicated in parentheses (sex and participant number, age, race).

$A=$ African American; $A P E=$ alternative plan evaluation; $F=$ female; $I S=$ information search; $M=$ male; $P D E=$ postdecision evaluation; $P N R=$ problem $/$ need recognition; $P S D=$ plan selection decision; $W=$ White . 


\section{FIGURE 2 A Conceptual Model of Medicare Plan Selection Decision-Making Process and Influencing Factors}

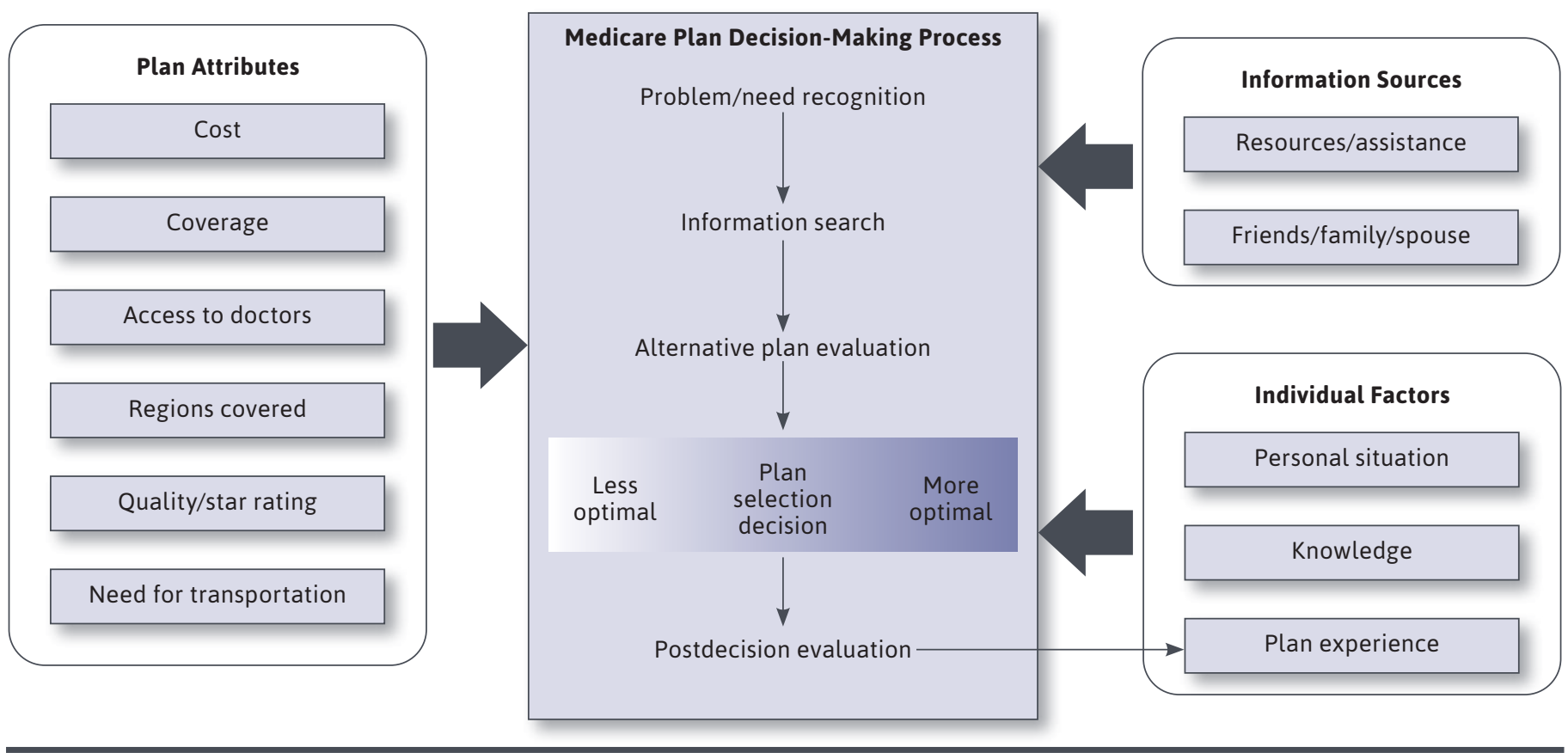

compensatory decision-making process involving tradeoffs tends to be cognitively intensive but often believed to result in more "normatively accurate" decisions than do other heuristics-based decision-making processes. ${ }^{40}$ However, most interviewees showed characteristics of bounded rationality, instead. A majority of the interviewees (65\%) chose to stick to the status quo (keeping their existing plan) and $25 \%$ acquiesced to a recommendation by family/ friends or another source without a thorough alternative plan evaluation.

Some of the previously mentioned decision-making process codes may also be secondarily related to other CDM-based decision-making steps by influencing or being influenced by them. For example, although sticking to the status quo may be primarily a characteristic of the PSD step of the Medicare decision-making process, both the CDM and our data suggest that this characteristic may be influenced by beneficiaries' favorable assessment of their existing plan (the postdecision evaluation [PDE] step), which may prevent them from recognizing a problem or a need to switch plans (the problem/need recognition [PNR] step), thereby discouraging them from seeking additional information on other alternative plans (the IS step) or biasing their evaluation of alternative plans in favor of their existing plan (the APE step). This example illustrates how the 5 steps of the Medicare decision-making process are closely linked together to lead to a final plan selection decision by a beneficiary.

\section{CONCEPTUAL MODEL}

Drawing from the CDM and the study findings, we developed a conceptual model illustrating a 5-step (PNR-IS-APE-PSDPDE) Medicare plan selection decision-making process and the influential factors affecting the process (Figure 2). ${ }^{25,28}$ Similar to the CDM, after recognizing a need to select a plan (the PNR step), beneficiaries start searching for information/resources about Medicare plan options and attributes (the IS step). Given the information learned, alternative Medicare plans are evaluated and compared based on a set of decision preferences (the APE step), and finally a plan is selected (the PSD step). Depending on beneficiaries' level of involvement in each of these steps, they may follow a more or less rational decision-making route, resulting in staying in the current plan or switching to another plan, which may be more or less optimal. The utilization experience with a plan is evaluated (the PDE step), which may affect the beneficiaries' future plan selection decision.

Further, the conceptual model incorporates the influential factors identified in this study, including plan attributes, information sources, individual factors of knowledge, 
personal situation, and experience, which are mapped around the 5-step decision-making process. These factors are likely to exert influences, individually or interactively, on various characteristics that beneficiaries manifest across the 5 steps of decision making. When making a plan selection decision, beneficiaries assess plan attributes such as cost, coverage, and physician access. Additionally, elements of decision making, such as the degree of the problem/ need recognized, the extent of information searched, the diversity of plans evaluated, and the decision strategy used by beneficiaries may be affected by individual predisposing factors including their knowledge of Medicare and its plans, experience with Medicare plans, and personal situation such as health status. Beneficiaries' information sources also influence their choices and the final plan selection.

The model provides essential elements for researchers to consider in examining beneficiary decision making and stimulate research in health care or decision-making areas. The model could also offer guidance for designing assistance interventions targeting beneficiaries at different stages through the decision-making process.

\section{Discussion}

Existing literature has defined optimal plan selection as selecting the plan with the lowest estimated out-of-pocket costs. ${ }^{19-21,29}$ However, beneficiaries did not consistently select the most economical plan.19,30 Similarly, in our study, although cost was mentioned by all study participants, many other plan attributes have critical impact on their plan selection decision. Therefore, we argue that an optimal plan is not always the most economical option. Rather, it is a plan that the participant is satisfied with after engaging in a thorough patient-centric decision-making process. To help Medicare beneficiaries make thorough patient-centric decisions, it is necessary for people who assist Medicare beneficiaries in plan selection to educate beneficiaries about the importance of evaluating Medicare plans and inform them of diverse plan attributes to consider when selecting Medicare plans. ${ }^{13}$

Beneficiaries' individual characteristics, including Medicare knowledge, personal situation, and plan experience were cited as influential factors in existing literature. For example, some older adults are vulnerable to suboptimal plan selection due to possible changes in cognitive function and limited numeracy and health literacy skills, compounded by a lack of awareness regarding cost-saving Medicare subsidy programs. ${ }^{20,21,31-34}$ Although our study did not measure cognitive function, numerical literacy, or health literacy, the study team did not notice significantly declined cognitive function or limited health literacy that would prevent interviewees from participating in the study. Instead, the status and changes in personal situations, such as anticipated health care utilization, residential location, and plan eligibility, affected participants' plan selection.

Additionally, plan selection assistance from others was critical among our participants. The Centers for Medicare \& Medicaid Services disseminates plan information by interactive web page. Although delivering plan information via internet is efficient, it may have limited reach, especially to those living in rural areas and/or those who may not have access to the internet or may not own a computer. ${ }^{35}$ For example, in Alabama, 55 of 67 counties are designated as rural areas and a large portion of the state is medically underserved. ${ }^{36}$ The residents also have limited access to assistance from health care professionals, such as pharmacists, who are capable of helping with plan selection. ${ }^{37}$ Therefore, it is not a surprise that these participants may reach out to SHIP, ${ }^{38}$ insurance providers, or their friends and families for plan selection assistance.

We uncovered that the plan selection decision-making process among Medicare beneficiaries could be explained within the CDM's 5 steps of consumer decision-making process. ${ }^{25}$ Information-processing capability and task environment interact to shape people's behaviors. ${ }^{39}$ Individuals who are more capable of information processing "set priorities" and "weigh the trade-offs" when they undergo a rational decision-making process. ${ }^{40}$ In contrast, the rationality of some participants in selecting a plan is limited to some extent by unknown future health status, an overload of information, or individuals' cognitive limitations; in such cases, beneficiaries may rely on schema-based mechanisms to make complex decisions, including generalizations from past experience, engaging in an unsystematic decisionmaking process, and spending less time thinking about all aspects of a given decision choice..$^{41}$ The difference between individuals' actions may also be due to different Medicare knowledge levels and health status, as people who are more knowledgeable and have better health status may be more involved in plan selection and switching. ${ }^{11,13}$ Thus, it is desired that assistance/intervention programs are designed to take these varying factors and decision-making steps into consideration.

Furthermore, involvement of health care professionals in plan selection has been recommended by researchers, but has not been well implemented..$^{42,43}$ The majority (85\%) of our participants selected plans that maintain their access to specific physicians, and more than half (55\%) compared plans against their anticipated health care needs. Therefore, involving physicians in the plan selection process could help identify necessary health care needs and promote efficient plan selection. Though physicians and patients define "good 
treatments" in different ways due to discordance in goals and prioritization of care, ${ }^{44,45}$ shared decision making may increase communication to reach consensus in terms of preferred treatments and achieve better treatment outcomes. ${ }^{45-47}$ Moreover, pharmacists could assist in multiple steps through the decision-making process. Because pharmacists frequently encounter patients who need financial support for their medications, ${ }^{48,49}$ they are in a unique position to help patients recognize the need to switch plans in a timely fashion, navigate plan alternatives, and provide medication cost-saving strategies. ${ }^{50}$

Finally, addressing accuracy of information provided by people who assist Medicare beneficiaries in plan selection is critical. Several participants of our study reported they had been contacted by "Medicare people," who introduced available plans and led the beneficiaries in deciding between limited options offered by 1 commercial company. None of our participants suspected the legitimacy of these phone calls or were aware of the need to check the legitimacy of these companies. Selecting a plan recommended in this manner may contribute to inappropriate plan selection. Though SHIP offices in each state provide free and unbiased assistance and counseling and Senior Medicare Patrol educates communities to promote preventative awareness of health care fraud, ${ }^{51}$ these programs have limited reach. Future efforts should build a systematic monitoring, consulting, and feedback mechanism to provide reliable protection for Medicare beneficiaries.

\section{LIMITATIONS}

This study has some limitations to consider. It was conducted by 3 interviewers, which raises the possibility of inconsistency among interviewers. ${ }^{52}$ Additionally, the study sample had a high proportion of highly educated individuals, which may introduce selection bias into the recruitment process. Furthermore, several participants referred by SHIP had previously received plan selection counseling services from SHIP; they may be more knowledgeable about Medicare, raising potential response bias. Finally, the study was conducted with Alabama residents, which limits the generalizability of the study findings.

\section{Conclusions}

This study uncovered that the plan selection decision-making process among Medicare beneficiaries is consistent with the consumer decision-making model. ${ }^{28}$ We created a conceptual model showing that plan attributes, information sources, and 3 individual factors (knowledge, personal situation, and experience) impact the 5-step plan selection decision-making process. The study provided a better understanding of the factors influencing Medicare beneficiaries' plan decisions. The findings may help researchers and community agencies design decision support interventions/tools to help Medicare beneficiaries make optimal decisions when selecting their Medicare plan.

\section{DISCLOSURES}

This study was supported by the Auburn University Undergraduate Research Program. The authors declare no conflicts of interest.

\section{REFERENCES}

1. Jacobson G, Freed M, Damico A, Neuman T; Kaiser Family Foundation. Medicare Advantage 2020 spotlight: first look. October 24, 2019. Accessed January 29, 2021. https://www.kff.org/ report-section/medicare-advantage2020-spotlight-first-look-data-note/
2. Kaiser Family Foundation. An overview of the Medicare Part D prescription drug benefit. October 14, 2020. Accessed January 29, 2021. https:// www.kff.org/medicare/fact-sheet/ an-overview-of-the-medicare-part-dprescription-drug-benefit/

3. Marzilli Ericson KM. Consumer inertia and firm pricing in the Medicare Part D prescription drug insurance exchange. Am Econ J: Econ Policy. 2014;6(1):38-64.

4. Kaiser Family Foundation. An overview of Medicare. February 13, 2019.

Accessed January 29, 2021. https:// www.kff.org/medicare/issue-brief/ an-overview-of-medicare $/$

5. Salive ME. Multimorbidity in older adults. Epidemiol Rev. 2013;35:75-83.

6. Avorn J. Part "D" for "defective"-the Medicare drug-benefit chaos. N Engl J Med. 2006;354(13):1339-41.

7. Han J, Ko DW, Urmie JM. The role of satisfaction and switching costs in Medicare Part D choices. Res Social Adm Pharm. 2014;10(2):398-407.

8. Buchmueller TC, Grazier K, Hirth RA, Okeke EN. The price sensitivity of Medicare beneficiaries: a regression discontinuity approach. Health Econ. 2013;22(1):35-51.

9. Boonen LH, Laske-Aldershof T, Schut FT. Switching health insurers: the role of price, quality and consumer information search. Eur J Health Econ. 2016;17(3):339-53.

10. Chi WC, Wolff J, Greer R, Dy S. Multimorbidity and decision-making preferences among older adults. Ann Fam Med. 2017;15(6):546-51.

11. Duijmelinck DM, van de Ven WP. Switching rates in health insurance markets decrease with age: empirical evidence and policy implications from the Netherlands. Health Econ Policy Law. 2016;11(2):141-59.

12. Henning-Smith C, Casey M, Moscovice I. Does the Medicare Part D decision-making experience differ by rural/urban location? J Rural Health. 2017;33(1):12-20. 
13. Polinski JM, Bhandari A, Saya UY, Schneeweiss S, Shrank WH. Medicare beneficiaries' knowledge of and choices regarding Part D, 2005 to the present. J Am Geriatr Soc. 2010;58(5):950-66.

14. Finucane ML, Mertz CK, Slovic P, Schmidt ES. Task complexity and older adults' decision-making competence. Psychol Aging. 2005;20(1):71-84.

15. Salthouse TA, Babcock RL. Decomposing adult age differences in working memory. Dev Psychol. 1991;27(5):763.

16. Morrell RW, Shifren K, Park D, eds. Processing of Medical Information in Aging Patients: Cognitive and Human Factors Perspectives. Mahwah, NJ: Lawrence Erlbaum Associates; 1999.

17. Bettman JR, Luce MF, Payne JW. Consumer decision making: a choice goals approach. In: Haugtvedt CP, Herr P, Kardes FR, eds. Handbook of Consumer Psychology. New York: Lawrence Erlbaum Associates; 2008.

18. Scheibehenne B, Greifeneder R, Todd PM. Can there ever be too many options? A meta-analytic review of choice overload. J Consumer Res. 2010;37(3):409-25.

19. Heiss F, Leive A, McFadden D, Winter J. Plan selection in Medicare Part D: evidence from administrative data. J Health Econ. 2013;32(6):1325-44.

20. Zhou C, Zhang Y. The vast majority of Medicare Part D beneficiaries still don't choose the cheapest plans that meet their medication needs. Health Aff. 2012;31(10):2259-65.

21. Abaluck J, Gruber J. Choice inconsistencies among the elderly: evidence from plan choice in the Medicare Part D program. Am Econ Rev. 2011;101(4):1180-210.

22. Stults CD, Baskin AS, Bundorf MK, Tai-Seale M. Patient experiences in selecting a Medicare Part D prescription drug plan. J Patient Exp. 2018;5(2):147-52.

23. De Natale ML. Understanding the Medicare Part D prescription program: partnerships for beneficiaries and health care professionals. Policy Polit Nurs Pract. 2007;8(3):170-81.
24. Jacobson G, Freed MF, Damico A, Neuman T. Kaiser Family Foundation. A dozen facts about Medicare Advantage in 2019. June 6, 2019. Accessed January 29, 2021. https://www.kff. org/medicare/issue-brief/a-dozenfacts-about-medicare-advantage-in2019/\#: :text=1.,doubled\%20over\%20 the $\% 20$ past $\% 20$ decade\&text=In\%20 2019\%2C\%20one\%2Dthird\%20(,rate\%20 in\%202017\%20and\%202018

25. Cox A, Granbois D, Summers J. Planning, search, certainty and satisfaction among durables buyers: a longitudinal study. 1983. Accessed January 29, 2021. https://www.acrwebsite.org/ volumes/6148/volumes/v10/NA-10

26. Vaismoradi M, Turunen H, Bondas T. Content analysis and thematic analysis: Implications for conducting a qualitative descriptive study. Nurs Health Sci. 2013;15(3):398-405.

27. Krippendorff K. Reliability in content analysis: Some common misconceptions and recommendations. Hum Commun Res. 2004;30(3):411-33.

28. Dudovskiy J. Consumer decision making process: a detailed analysis. Accessed January 29, 2021. https://research-methodology.net/ consumer-decision-making-process-adetailed-analysis/

29. Gruber J. Choosing a Medicare Part D plan: are Medicare beneficiaries choosing low-cost plans? March 2009. Accessed January 29. 2021. https://www.kff.org/ wp-content/uploads/2013/01/7864.pdf

30. Abaluck J, Gruber J. Choice inconsistencies among the elderly: evidence from plan choice in the Medicare Part D program. Am Econ Rev. 2011;101(4):1180-210.

31. Rudolph NV, Montgomery MA. Lowincome Medicare beneficiaries and their experiences with the part D prescription drug benefit. Inquiry. 2010;47(2):162-72.

32. Galal SM, Patel RA, Thai HK, et al. Impact of an elective course on pharmacy students' attitudes, beliefs, and competency regarding Medicare Part D. Am J Pharm Educ. 2012;76(5):91.
33. Perry M, Dulio A, Cubanski J. Voices of beneficiaries: Medicare Part D insights and observations one year later. December 2006. Accessed January 29, 2021. http://globalag.igc.org/health/ us/2006/kaiser.pdf

34. Patel RA, Lipton HL, Cutler TW, Smith AR, Tsunoda SM, Stebbins MR. Cost minimization of medicare part D prescription drug plan expenditures. Am J Manag Care. 2009;15(8):545-53.

35. Wright DW, Hill TJ. Prescription for trouble: Medicare Part D and patterns of computer and internet access among the elderly. J Aging Soc Policy. 2009;21(2):172-86.

36. Alabama Public Health. Selected indicators of health status in Alabama. Alabama's rural and urban counties. October 2007. Accessed February 12, 2021. https://www.alabamapublichealth.gov/ ruralhealth/assets/StatewideReport.pdf

37. Hiscock R, Pearce J, Blakely T, Witten K. Is neighborhood access to health care provision associated with individual-level utilization and satisfaction? Health Serv Res. 2008;43(6):2183-200.

38. Hohmann LA, Hastings TJ, McFarland SJ, Hollingsworth JC, Westrick SC. Implementation of a Medicare plan selection assistance program through a community partnership. Am J Pharm Educ. 2018;82(9):6452.

39. Simon HA. Invariants of human behavior. Ann Rev Psychol. 1990;41(1):1-20.

40. Bettman JR, Luce MF, Payne JW. Constructive consumer choice processes. J Consumer Res. 1998;25(3):187-217.

41. Carpenter SM, Yoon C. Aging and consumer decision making. Ann N Y Acad Sci. 2011;1235:E1-12.

42. Levinson W, Kao A, Kuby A, Thisted RA. Not all patients want to participate in decision making: a national study of public preferences. J Gen Intern Med. 2005;20(6):531-35. 
43. Edgman-Levitan S, Cleary PD. What information do consumers want and need? A synthesis of research to date, plus interviews with health plan managers and consumer advocates. Health Aff. 1996;15(4):42-56.

44. Devettere RJ. Practical Decision Making in Health Care Ethics: Cases, Concepts, and the Virtue of Prudence. 3rd ed. Washington, DC: Georgetown University Press; 2010.

45. Douglas SL, Daly BJ, Meropol NJ, Lipson AR. Patient (Pt) and oncologist (MD) discordance in goals of care in end of life (EOL) decision making. J Clin Oncol. 2018;36(15 Suppl):10007.Accessed January 29, 2021. https://ascopubs.org/doi/ abs/10.1200/JCO.2018.36.15_suppl.10007

46. Charles C, Gafni A, Whelan T.

Shared decision-making in the medical encounter: what does it mean? (or it takes at least two to tango). Soc Sci Med. 1997;44(5):681-92.
47. Peterson KA, Radosevich DM, O'Connor PJ, et al. Improving diabetes care in practice: findings from the TRANSLATE trial. Diabetes Care. 2008;31(12):2238-43.

48. Kennelty KA, Thorpe JM, Chewning B, Mott DA. Use of pharmacists or pharmacies as Medicare Part D information sources. J Am Pharm Assoc. 2012;52(6):e205-09.

49. Westrick SC, Hastings TJ, McFarland SJ, Hohmann LA, Hohmann NS. How do pharmacists assist Medicare beneficiaries with limited income? A cross-sectional study of community pharmacies in Alabama. J Manag Care Spec Pharm. 2016;22(9):1039-45. doi: 10.18553/ jmcp.2016.22.9.1039
50. Stebbins MR, Frear ME, Cutler TW, et al. Pharmacy students teaching prescribers strategies to lower prescription drug costs for underserved patients. J Manag Care Pharm. 2013;19(7):534-41. doi: 10.18553/jmcp.2013.19(7):534-41.

51. Lischko A, Reich AJ, Chui K, Koch-Weser S. Evaluation of the senior Medicare Patrol Program. Gerontologist. 2016;56(Suppl 3):747. Accessed January 29, 2021. https://academic. oup.com/gerontologist/article/56/ Suppl_3/747/2576749

52. Matteson SM, Lincoln YS. Using multiple interviewers in qualitative research studies: the influence of ethic of care behaviors in research interview settings. Qual Inquiry. 2009;15(4):659-74. 